\title{
M-generalised q-neutrosophic MULTIMOORA for Decision Making
}

\author{
Edmundas Kazimieras ZAVADSKAS ${ }^{1 *}$, Romualdas BAUSYS ${ }^{2}$, \\ Ingrida LESCAUSKIENE ${ }^{2}$, Jamal OMRAN ${ }^{3}$ \\ ${ }^{1}$ Vilnius Gediminas Technical University, Institute of Sustainable Construction, \\ Saulètekio Ave. 11, LT-10223 Vilnius, Lithuania \\ edmundas.zavadskas@vgtu.lt (*Corresponding author) \\ ${ }^{2}$ Vilnius Gediminas Technical University, Department of Graphical Systems, \\ Saulètekio Ave. 11, Vilnius, LT-10223, Lithuania \\ romualdas.bausys@vgtu.lt, ingrida.lescauskiene@vgtu.lt \\ ${ }^{3}$ Tishreen University, Department of Construction Engineering and Management, \\ Lattakia, Syria \\ j-omran@tishreen.edu.sy
}

\begin{abstract}
Different frameworks can be chosen to solve multicriteria decision making (MCDM) problems emerging in business, economy, health care, engineering and other areas. Uncertainty, vagueness and non-rigid boundaries of the initial information are frequently noticed when dealing with the practicalities of the MCDM tasks. Single-valued neutrosophic sets are considered as the effective tool to express uncertainty of the information, however in some cases it lacks the desirable generality and flexibility. The m-generalized q-neutrosophic sets (mGqNNs) were recently proposed to deal with this situation. The novel MCDM methodology MULTIMOORA-mGqNN is presented in this paper. An illustrative example that analyses the effectiveness of different cable root management decisions for the application in chemical industry is also provided to demonstrate the practicalities of the MULTIMOORA-mGqNN.
\end{abstract}

Keywords: Multicriteria decision making, MULTIMOORA, Neutrosophic sets, Cable root management.

\section{Introduction}

Nowadays, different decision-making frameworks have been proposed to solve the real-time problems emerging in business, economy, health care, engineering and other areas. In many cases, the initial decision-making information cannot be strictly characterised because of its incompleteness, indeterminacy and inconsistency. Therefore, the researchers who focus on modern artificial intelligence methods are looking for the mathematical modelling techniques that can be applied to solve various problems with the uncertainty and vagueness of the decision information.

The fuzzy set theory was proposed by Zadeh (1965) as the solution to incorporate the uncertainty, vagueness and non-rigid boundaries of the initial information into the mathematical models. By this theory, each object of the universe is described by the single relatively graded membership and non-membership.

Brauers, Baležentis \& Baležentis (2011) proposed MULTIMOORA (Multiobjective Optimisation by Ratio Analysis Plus Full Multiplicative Form) under the fuzzy sets for the multicriteria decisionmaking problems.
Stanujkic et al. (2019) constructed the modification of the MULTIMOORA method that was able to work under the bipolar fuzzy set environment. Bipolar fuzzy sets introduce positive and negative membership functions. Positive membership function represents the satisfaction degree of the object modelled by the bipolar-valued fuzzy set, and the negative membership function signifies the satisfaction degree of the counter-property modelled by the bipolar-valued fuzzy set.

The fuzzy MULTIMOORA method was combined with the partial least squares path by Maghsoodi et al. (2019). They declared that this approach and the proposed statistical method validate each other to present an optimal solution for the assessment of the criteria influencing job satisfaction.

Since it is not always true that the sum of the membership and non-membership degree can be equalled to one, Atanassov (1986) introduced intuitionistic fuzzy sets (IFN) to incorporate the degree of hesitation into the decisionmaking processes. In 2014, Balezentis, Zeng \& Balezentis (2014) proposed MULTIMOORAIFN, where different intuitionistic fuzzy power 
ordered aggregation operators were determined to improve the robustness of the decision-making processes. MULTIMOORA under Interval-valued intuitionistic fuzzy sets (IVIF-MULTIMOORA) was analysed by (Zavadskas et al., 2015) to handle the uncertainty in the group decisionmaking processes. Choquet integral operators were proposed by Liao et al. (2019) to create the MULTIMOORA modification under the hesitant fuzzy linguistic sets.

Since the intuitionistic fuzzy set theory requires to keep the sum of the membership and nonmembership degrees in the closed interval $[0,1]$, it also raises some limitations for the application into the real-life decision problems.

In order to overcome these limitations, Yager (2013) proposed Pythagorean fuzzy sets, where the membership degree $\zeta$ and non-membership degree $\vartheta$ follow the requirement $\zeta^{2}+\vartheta^{2} \leq 1$. This feature allows for accommodating additional uncertainties of the initial information. Since the mutual support was noticed between the input arguments, power average and power geometric operators, MULTIMOORA by the interval-valued Pythagorean fuzzy set was proposed by Liang et al. (2020).

The q-rung orthopair fuzzy sets are the new extension of the intuitionistic fuzzy sets and Pythagorean fuzzy sets (Yager, 2017). The q-rung orthopair fuzzy sets are governed by the condition that the summation of $q^{\text {th }}$ power of the membership function and the $\mathrm{q}^{\text {th }}$ power of the nonmembership grade are limited in the interval $[0,1]$. Applying this set q-rung orthopair fuzzy Hamacher weighted average operator and q-rung orthopair fuzzy Hamacher weighted geometric average operator is proposed and implemented in MULTIMOORA method (Zhu, 2020). Dombi prioritised aggregations were developed on q-rung orthopair fuzzy sets and integrated into the MULTIMOORA approach proposed by Aydemir \& Yilmaz Gündüz (2020).

In 1999, the concept of the neutrosophic sets was proposed by Smarandache (1999). Neutrosophic sets (NS) are the generalisation of the fuzzy logic, that deals with the knowledge of the neural though; therefore, it is able to analyse the greater amount of uncertainty. By the NS logic, each parameter of the analysed problem can be represented by the degree of the truth $(\mathrm{T})$, the degree of the indeterminacy (I) and the degree of the falsity (F). Neutrosophic sets also have high flexibility because they are able to handle totally independent components as well as the partially independent and partially dependent elements. The intuitionistic fuzzy set cannot deal with these conditions (Wang, Smarandache \& Zhang, 2010). Besides, differently from intuitionistic fuzzy sets, the value of the indeterminacy degree is independent of truth and falsity degrees in the neutrosophic logic.

Because of the advantages proposed earlier, the increased popularity of the neutrosophic sets can be noticed. MULTIMOORA under single-valued neutrosophic sets were employed in different MCDM tasks where the solution capable of dealing with the indeterminacy of the initial information were required (Stanujkic et al., 2017; Zavadskas et al., 2017; Zavadskas et al., 2019).

In 2019, Smarandache (2019) proposed a concept of neutrosophic sets as the generalisation of the classical fuzzy, intuitionistic fuzzy (IFS), q-rung orthopair fuzzy and Pythagorean fuzzy sets. Based on this concept, Saha et al. (2020) extended this type of the generalisation and introduced a notation of the m-generalized q-neutrosophic sets (mGqNSs). New operational laws and properties of the mGqNSs were also introduced.

The goal of this paper is mainly dedicated to the implementation of the concept of m-generalized q-neutrosophic sets (mGqNSs) into the framework of the MULTIMOORA method, namely MULTIMOORA-mGqNN. The practical application will also be presented.

Preliminaries of m-generalized q-neutrosophic sets $(m G q N N s)$ will be presented in Section 2 . The core of the novel MULTIMOORA modification for the m-generalized q-neutrosophic sets will be described in Section 3. Finally, practical application of the MULTIMOORA - mGqNN will be presented for the selection of the best cable routes in the chemical industry. 


\section{M-generalized q-neutrosophic Sets}

The preliminaries of m-generalized q-neutrosophic sets ( $m G q N N s)$ will be presented in this section. The $m G q N N s$ is the generalisation of fuzzy sets such as Pythagorean fuzzy set, intuitionistic fuzzy set, q-rung orthopair fuzzy set, singlevalued neutrosophic set. Operations between m-generalized q-neutrosophic numbers will also be presented.

\subsection{Definition}

Suppose $U$ is a universe set and $x \in U$. Then a single-valued neutrosophic set $\psi$ is determined as:

$\psi=\{\langle x, \xi(x), \vartheta(x), \eta(x)\rangle: x \in U\}$

Where the functions $\xi, \vartheta, \eta: U \rightarrow[0,1]$ follows the condition $0 \leq \xi(x)+\vartheta(x)+\eta(x) \leq 3$. The functions $\xi(x), \vartheta(x), \eta(x)$ describe the truthmembership, indeterminacy-membership and falsity membership degree.

\subsection{Definition}

Suppose $U$ is a universe set and $x \in U$. Then $m G q N s$ is described as:

$\psi=\{\langle x, \xi(x), \vartheta(x), \eta(x)\rangle: x \in U\}$

Here $\xi, \vartheta, \eta: U \rightarrow[0, r]$ and $(0<r \leq 1)$.

The $\xi, \vartheta, \eta$ are the functions where:

$0 \leq \xi(x), \vartheta(x), \eta(x) \leq 1$

$0 \leq(\xi(x))^{q}+(\vartheta(x))^{q}+(\eta(x))^{q} \leq \frac{3}{m} ;$

$m, q \geq 1$.

Then $x \in U$, the functions $\xi(x), \vartheta(x), \eta(x)$ correspond to m-generalised truth membership, $\mathrm{m}$-generalised indeterminacy membership and $\mathrm{m}$-generalised falsity membership. The triplet $\psi=\langle\xi, \vartheta, \eta\rangle$ is called $\mathrm{m}$-generalized q-neutrosophic number $m G q N N$, where $m$ and $q$ values can be used to cover different variations of fuzzy sets.

\subsection{Definition}

Suppose $\psi_{1}=\left\langle\xi_{1}, \vartheta_{1}, \eta_{1}\right\rangle$ and $\psi_{2}=\left\langle\xi_{2}, \vartheta_{2}, \eta_{2}\right\rangle$ are two $\mathrm{m}$-generalized q-neutrosophic numbers defined in the universe set $U$ and $\lambda$ is any real number $>0$.
Then the operations between m-generalized q-neutrosophic numbers ( $m G q N N)$ are:

$\psi_{1} \oplus \psi_{2}=$

$\left\langle\left(1-\left(1-\xi_{1}^{q}\right)\left(1-\xi_{2}^{q}\right)\right)^{\frac{1}{q}}, \quad \vartheta_{1} \vartheta_{2}, \quad \eta_{1} \eta_{2}\right\rangle$

$\psi_{1} \otimes \psi_{2}=\left\langle\xi_{1} \xi_{2}\right.$,

$\left(1-\left(1-\vartheta_{1}^{q}\right)\left(1-\vartheta_{2}^{q}\right)\right)^{\frac{1}{q}}$

$\left.\left(1-\left(1-\eta_{1}^{q}\right)\left(1-\eta_{2}^{q}\right)\right)^{\frac{1}{q}}\right\rangle$

$\lambda * \psi_{1}=$

$\left\langle\left(1-\left(1-\xi_{1}^{q}\right)^{\lambda}\right)^{\frac{1}{q}}, \quad \vartheta_{1}^{\lambda}, \quad \eta_{1}^{\lambda}\right\rangle$

$\lambda \odot \psi_{1}=<\xi_{1}^{\lambda}$,

$\left(1-\left(1-\vartheta_{1}^{q}\right)^{\lambda}\right)^{\frac{1}{q}}$

$\left(1-\left(1-\eta_{1}^{q}\right)^{\lambda}\right)^{\frac{1}{q}}>$

$\psi_{1}^{c}=\left\langle\xi_{1}, \vartheta_{1}, \eta_{1}\right\rangle$

\subsection{Definition}

Calculation of the $m G q N N \psi=\langle\xi, \vartheta, \eta\rangle$ score $S(\psi)$ is done by:

$S(\psi)=\frac{3+3 \xi^{q}-2 \vartheta^{q}-\eta^{q}}{6}$

If $\psi=\langle\xi, \vartheta, \eta\rangle$ and $\psi^{\prime}=\left\langle\xi^{\prime}, \vartheta^{\prime}, \eta^{\prime}\right\rangle$ are two $\mathrm{m}$-generalized q-neutrosophic numbers, the ranking of them is performed by the following rules:

If $S(\psi)>S\left(\psi^{\prime}\right)$, then $\psi>\psi^{\prime}$

If $S(\psi)=S\left(\psi^{\prime}\right)$, then $\psi=\psi^{\prime}$

\section{MULTIMOORA under m-generalized q-neutrosophic Sets}

The essence of the novel approach MULTIMOORAmGqNN consists in the operational functionality of m-generalized q-neutrosophic sets and crisp MULTIMOORA extensions described by Brauers \& Zavadskas (2011). 
Step 1. The initial step in the multicriteria decision-making methods is the construction of the initial decision matrix $X$ with elements $x_{i j}$ corresponding to the $i^{\text {th }}$ criteria of $j^{\text {th }}$ alternative.

Step 2. The normalisation of the decision matrix elements is performed by vector normalisation, that was developed for appropriate estimation of the certain features of the neutrosophic sets.

$$
\mathrm{X}^{*}=\frac{x_{i j}}{\sqrt{\sum_{i=1}^{m} x_{i j}^{2}}}
$$

The proposed normalisation function ensures better stability and resolution range for the proposed MULTIMOORA- mGqNN approach.

Step 3. After the normalisation the neutrosophication of the decision matrix should be performed. The crisp values are converted into neutrosophic numbers applying the standard modification rates as in (Zavadskas et al., 2017) The novel neutrosophic decision matrix is created from the elements $\left(x_{\psi}^{*}\right)_{i j}$.

Step 4. The first target of m-generalized q-neutrosophic MULTIMOORA proposal is the application of the ratio system. It can be described as:

$$
Q_{j}=\sum_{i=1}^{g} w_{i}\left(x_{\psi}^{*}\right)_{i j}+\left(\sum_{i=g+1}^{n} w_{i}\left(x_{\psi}^{*}\right)_{i j}\right)^{c}
$$

Where $g$ elements match members of beneficial criteria, $n-g$ match members of non-beneficial criteria.

Step 5. Calculation of the second objective of m-generalized q-neutrosophic MULTIMOORA approach. The second objective is established, taking into account deviation from the reference point and the Min-Max metric of Tchebycheff norm:

$$
\min _{j}\left(\max _{i}\left|D\left(r_{i}-w_{i}\left(x_{n}^{*}\right)_{i j}\right)\right|\right)
$$

For the beneficial parameters the reference point is calculated by the formula:

$r_{i}=\max _{i}\left(w_{i}\left(x_{n}^{*}\right)_{i j}\right)$

The reference point for the non-beneficial parameters $r_{i}$ is defined as: $r_{i}=\min _{i}\left(w_{i}\left(x_{n}^{*}\right)_{i j}\right)$

The distance measure between two m-generalized q-neutrosophic sets is determined as follows:

$D\left(\psi_{1}, \psi_{2}\right)=$
$\sqrt{\frac{1}{3}\left(\left(\xi_{1}^{q}-\xi_{2}^{q}\right)^{2}+\left(\vartheta_{1}^{q}-\vartheta_{2}^{q}\right)^{2}+\left(\eta_{1}^{q}-\eta_{2}^{q}\right)^{2}\right)}$

The matching of the neutrosophic members is done applying the score function as followed in Equation (6).

Step 6. The third objective of the proposed neutrosophic MULTIMOORA expression analyses Full Multiplicities form. It is implemented as the minimisation of purely multiplicative utility function. Therefore, for each of the alternatives, the overall utility function can be described as:

$U_{j}=\frac{S\left(A_{j}\right)}{S\left(B_{j}\right)}$

Here $A_{j}$ and $B_{j}$ components are calculated as:

$$
\begin{aligned}
& A_{j}=\prod_{i=1}^{g} w_{i}\left(x_{\psi}^{*}\right)_{i j} \\
& B_{j}=\prod_{j=g+1}^{n} w_{i}\left(x_{\psi}^{*}\right)_{i j}
\end{aligned}
$$

Here $A_{j}$ is the product of maximised parameters of $j^{\text {th }}$ alternative represented by the first component. The product of minimised parameters of $j^{\text {th }}$ alternative described by the second component is determined as $B_{j}$.

Step 7. The final summary of first, second and third objectives of the proposed method is completed within the dominance theory framework (Brauers \& Zavadskas, 2011).

\section{Application Example from Chemical Industrial Construction}

In this section, the multicriteria decision-making problem dedicated to the selection of the best cable routes in the chemical industry will be presented. MULTIMOORA - mGqNN approach will be employed for this task.

Cable routes are connections between electric power distribution systems and the customers 
in the production facilities. They serve for the transmission of electro-energy, the transmission of protection signals, control and information systems. Due to the complexity in terms of material, energetic and informational interdependence, a more detailed investigation of the choice of route management seems necessary.

Highly loaded track laying on the company premises and high risk of environmental and operational influences such as corrosion, fire and explosion risks, effects of chemicals, steam and other foreign media lead to a complex decision. This makes the best possible choice of cable laying method an interdisciplinary task that is technically and technologically used to examine both the electrical engineering and construction industries.

\subsection{Choice of the Parameters}

Both the internal and external parameters influence the quality of the cable laying methods applied in decision-making processes.

Internal influence parameters can be divided into two groups: territorial and site plan parameters and construction-related parameters.

Territorial and site plan parameters express the spatial conditions for the particular route and its relationships with other facilities. Four parameters fall into this group:

- $\quad$ C1. Space requirement. The routeing width is chosen as the dimension. For the underground construction, the width is specified as zero, whereby the trafficability must be warranted by appropriate laying depth.

- C2. Freedom of intersection. The evaluation of this parameter can be performed on the 10-point scale.

- C3. Connection between customer installations and routes. The cable routes in buildings and facilities can also be analysed regarding their connection options: above-ground introduction through the roof; above-ground introduction at the same height as the route; above-ground introduction; ground-level introduction; underground introduction.
C4. Space requirements for the construction site during the construction or repair work. This parameter is important since the limited space has a relevant impact on the decision.

Construction-related parameters. Five parameters that are related to $1 \mathrm{~m}$ of track length fall into this category:

C5. Construction time. In the chemical plant, the use of machines for shaft work can only be limited due to the spacerelated conditions. Thus, large components must be carried out manually, and it has considerable consequences for the construction period.

- C6. Construction costs. This is the cost of the investment, apart from the cost of cable laying. The variants vary cost-effectively, e.g. the costs for a walk-in channel are 12 times higher than for concrete sleepers.

- C7. Resources need. The earthwork capacities and assembly capacities are the main resources. When designing the capacities, the technological conditions of the construction work offer a great deal of flexibility.

- C8. Extension possibilities. In practice, the production facilities are often expanded; therefore, the cable trays must also have the ability to be equipped. Therefore, the costs incurred for extensions of the route are the important factors for the analysed decision-making.

- C9. Cable recovery. The processes related to the recovery of the cable can be examined concerning the accessibility to the cables. This parameter can be assessed on a 10 -point scale.

External influence parameters can be divided into two groups: environmental influence parameters and operational parameters.

Environmental influence parameters. Three parameters related with the environmental features in the surrounding of the cable lay systems were determined:

- C10. Risk of corrosion. When laying in soil, it must be taken into account that the cables may be at risk of corrosion as a result of deposits of industrial products in the soil. 
Depending on the specific floor effect, the cables must be laid with external protective covers. If necessary, cables should be laid in sealed plastic tubes (for non-specifically rated sheath).

- C11. Fire risk. The fire risk on cable systems arises primarily due to the influence of the external sources. Underground laid cables have low fire hazard since they hardly form a combustible system (according to fire physics). In the case of cables laid in the air, fire may occur due to sources of ignition. With regard to the risk of fire, the 10-point scale is used for the assessment.

- C12. Explosion risk. Cable systems do not belong directly to the workplaces that are in danger of explosion. But there is a risk that the explosion might occur in the adjacent areas. Therefore, cable trays should be laid in the underground if the facilities that can cause detonation are located in the surroundings. Otherwise, above-ground cable laying system can be chosen.

Operational parameters characterise the electrotechnical commissioning of the routes. Three criteria were determined in this category:

- C13. Occurring errors (error frequency). 50\% of all the detected errors faults are caused by the mechanical influences, therefore the cable lays that include bridges and the cable fences have certain advantages against the other laying methods. Precise information on the error frequencies is not possible for many reasons; therefore, the expert-based evaluation was chosen for the assessment of this parameter.

- C14. Effort for troubleshooting: (interruption time, downtime costs). The interruption time includes the time to find the cable fault, to create the mounting conditions or to repair the cable. Troubleshooting is also associated with the downtime costs, since the manhole capacity is often needed for error detection. Downtime costs are made up of the costs for troubleshooting, the repair costs and the costs for possible production failures.

- C15. Fire protection. With the laying options in earth, the costs for special fire protection measures are eliminated. Only the aboveground cable systems must be protected against the effects of fire, as well as the cables in canals.

The direct weighting technique was applied to determine initial weights of the internal and external parameters. At the first step, $50 \%$ of the weights were determined for the internal, and the other $50 \%$ were assigned to the external parameters. Then the weights were split among the parameters according to their importance for the final decision.

The list of all the parameters, their measures, optimums and the weighting information necessary for the decision-making are presented in Table 1.

Table 1. Parameter list and their weights

\begin{tabular}{|c|c|c|c|c|}
\hline ID & $\begin{array}{l}\operatorname{Min} / \\
\operatorname{Max}\end{array}$ & Description & Metrics & Weight \\
\hline \multicolumn{5}{|c|}{ INTERNAL PARAMETERS } \\
\hline \multicolumn{5}{|c|}{ Territorial and site plan parameters } \\
\hline $\mathrm{C}_{1}$ & MIN & $\begin{array}{c}\text { Space } \\
\text { requirement }\end{array}$ & $\mathrm{m}$ & $2.5 \%$ \\
\hline $\mathrm{C}_{2}$ & MIN & $\begin{array}{l}\text { Freedom of } \\
\text { intersection }\end{array}$ & Scale & $2.5 \%$ \\
\hline $\mathrm{C}_{3}$ & MAX & $\begin{array}{l}\text { Connection } \\
\text { between } \\
\text { customer } \\
\text { installations } \\
\text { and routes }\end{array}$ & Scale & $2.5 \%$ \\
\hline $\mathrm{C}_{4}$ & MAX & $\begin{array}{l}\text { Space } \\
\text { requirements } \\
\text { for the } \\
\text { construction site }\end{array}$ & $\mathrm{m}$ & $2.5 \%$ \\
\hline \multicolumn{5}{|c|}{ Construction-related parameters } \\
\hline $\mathrm{C}_{5}$ & MIN & $\begin{array}{c}\text { Construction } \\
\text { time }\end{array}$ & $\mathrm{h}$ & $15.0 \%$ \\
\hline $\mathrm{C}_{6}$ & MIN & $\begin{array}{l}\text { Construction } \\
\text { costs }\end{array}$ & $\$$ & $15.0 \%$ \\
\hline $\mathrm{C}_{7}$ & MIN & Resources need & Man & $5.0 \%$ \\
\hline $\mathrm{C}_{8}$ & MIN & $\begin{array}{c}\text { Extension } \\
\text { possibilities }\end{array}$ & $\$$ & $2.5 \%$ \\
\hline $\mathrm{C}_{9}$ & MIN & Cable recovery & Scale & $2.5 \%$ \\
\hline \multicolumn{5}{|c|}{ EXTERNAL PARAMETERS } \\
\hline \multicolumn{5}{|c|}{ Environmental Influence Parameters } \\
\hline $\mathrm{C}_{10}$ & MIN & Risk of corrosion & Scale & $10.0 \%$ \\
\hline $\mathrm{C}_{11}$ & MIN & Fire risk & Scale & $10.0 \%$ \\
\hline $\mathrm{C}_{12}$ & MIN & Explosion risk & Scale & $10.0 \%$ \\
\hline \multicolumn{5}{|c|}{ Operational parameters } \\
\hline $\mathrm{C}_{13}$ & MIN & $\begin{array}{l}\text { Occurring errors } \\
\text { (error frequency). }\end{array}$ & Scale & $7.5 \%$ \\
\hline $\mathrm{C}_{14}$ & MIN & $\begin{array}{c}\text { Effort for } \\
\text { troubleshooting }\end{array}$ & Scale & $7.5 \%$ \\
\hline $\mathrm{C}_{15}$ & MIN & Fire protection & Scale & $5.0 \%$ \\
\hline
\end{tabular}




\subsection{Description of Alternatives}

Nine alternatives presented as the different types of cable laying will be investigated in this paper:

- Cable tray (CT);

- Walk-in cable channel (WCC);

- Non-accessible channel, cable trough (NAC);

- Flattening at ground level (GL);

- Concrete threshold, open cable laying (CTH);

- $\quad$ Cable bridge (CB);

- Cable moulding stones (CMS);

- Combined cable and pipe bridge (CPB).

- $\quad$ Cable Fence (CF).
All nine alternatives are going to be assessed using the m-generalised q-neutrosophic sets. Parameters $\mathbf{C}_{1-} \mathbf{C}_{15}$ are going to be used as the attributes of the alternatives. The quantitative estimation of the internal influence quantities on $1 \mathrm{~m}$ length of the investigated routes are provided in Table 2. The values of the external variables associated with operational and environmental influences are shown in Table 3.

Once all the information required has been prepared for the decision-making processes, neutrosophication of the initial decision matrix was done (Table 4).

For this case, the values $m=1$ and $\mathrm{q}=2$ are chosen for the m-generalized q-neutrosophic numbers.

Then, the tree objectives of the MULTIMOORA were calculated by applying the m-generalized q-neutrosophic equations (8-14). Values for the neutrosophic ratio system, the neutrosophic

Table 2. Quantitative estimation of the internal influence quantities on $1 \mathrm{~m}$ length of the investigated routes

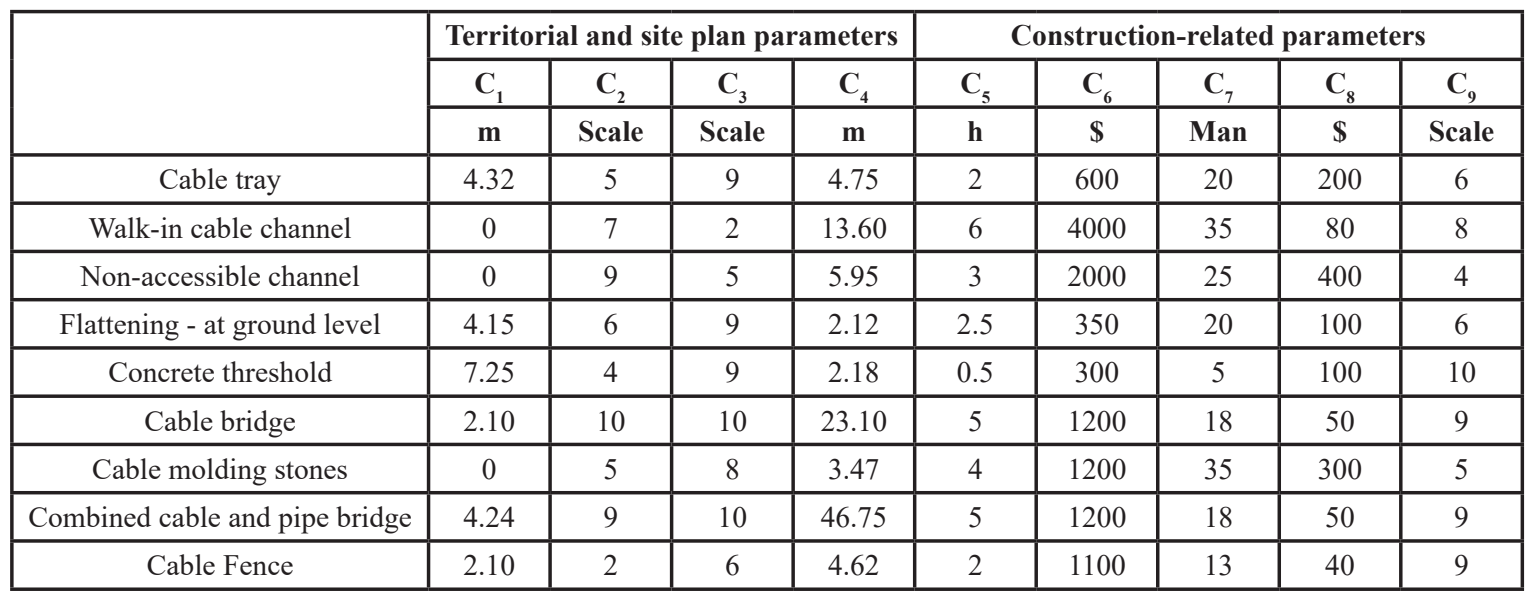

Table 3. External parameters of the system

\begin{tabular}{|c|c|c|c|c|c|c|}
\hline & \multicolumn{2}{|c|}{ Environmental Influence Parameters } & \multicolumn{3}{c|}{ Operational parameters } \\
\cline { 2 - 7 } & $\mathbf{C}_{\mathbf{1 0}}$ & $\mathbf{C}_{\mathbf{1 1}}$ & $\mathbf{C}_{\mathbf{1 2}}$ & $\mathbf{C}_{\mathbf{1 3}}$ & $\mathbf{C}_{\mathbf{1 4}}$ & $\mathbf{C}_{\mathbf{1 5}}$ \\
\hline Cable tray & 3 & 1 & 1 & 7 & 8 & 1 \\
\hline Walk-in cable channel & 5 & 4 & 2 & 2 & 3 & 10 \\
\hline Non-accessible channel & 4 & 3 & 2 & 2 & 6 & 8 \\
\hline Flattening - at ground level & 3 & 1 & 1 & 8 & 7 & 1 \\
\hline Concrete threshold & 2 & 5 & 5 & 5 & 1 & 3 \\
\hline Cable bridge & 8 & 7 & 8 & 1 & 2 & 5 \\
\hline Cable molding stones & 3 & 1 & 1 & 4 & 10 & 1 \\
\hline Combined cable and pipe bridge & 8 & 10 & 10 & 2 & 2 & 6 \\
\hline Cable Fence & 6 & 7 & 7 & 1 & 1 & 5 \\
\hline
\end{tabular}


Table 4. The neutrosophic matrix for the constructed decision-making problem

\begin{tabular}{|c|c|c|c|c|c|c|c|c|c|}
\hline & CT & WCC & NAC & GL & CTH & CB & CMS & CPB & CF \\
\hline$C_{1}$ & $\begin{array}{l}(0.4024, \\
0.6464, \\
0.5976)\end{array}$ & $\begin{array}{l}\text { (0.0009, } \\
0.9991, \\
0.9991)\end{array}$ & $\begin{array}{l}(0.0009, \\
0.9991, \\
0.9991)\end{array}$ & $\begin{array}{l}(0.3866, \\
0.6634, \\
0.6134)\end{array}$ & $\begin{array}{l}(0.6753, \\
0.2747, \\
0.3247)\end{array}$ & $\begin{array}{l}(0.1956, \\
0.8522, \\
0.8044)\end{array}$ & $\begin{array}{l}(0.0009, \\
0.9991, \\
0.9991)\end{array}$ & $\begin{array}{l}(0.395, \\
0.655, \\
0.605)\end{array}$ & $\begin{array}{l}(0.1956, \\
0.8522, \\
0.8044)\end{array}$ \\
\hline $\mathrm{C}_{2}$ & $\begin{array}{l}(0.2449, \\
0.8051, \\
0.7551)\end{array}$ & $\begin{array}{l}(0.3428 \\
0.7072 \\
0.6572)\end{array}$ & $\begin{array}{l}(0.4407, \\
0.5889, \\
0.5593)\end{array}$ & $\begin{array}{l}(0.2938, \\
0.7562, \\
0.7062)\end{array}$ & $\begin{array}{l}(0.1959, \\
0.8521, \\
0.8041)\end{array}$ & $\begin{array}{l}(0.4897, \\
0.5154, \\
0.5103)\end{array}$ & $\begin{array}{l}(0.2449, \\
0.8051, \\
0.7551)\end{array}$ & $\begin{array}{l}(0.4407 \\
0.5889, \\
0.5593)\end{array}$ & $\begin{array}{l}(0.0979, \\
0.9021, \\
0.9021)\end{array}$ \\
\hline $\mathrm{C}_{3}$ & $\begin{array}{l}(0.3763, \\
0.6737, \\
0.6237)\end{array}$ & $\begin{array}{l}(0.0836, \\
0.9164, \\
0.9164)\end{array}$ & $\begin{array}{l}(0.2091, \\
0.8409, \\
0.7909)\end{array}$ & $\begin{array}{l}(0.3763, \\
0.6737, \\
0.6237)\end{array}$ & $\begin{array}{l}(0.3763, \\
0.6737, \\
0.6237)\end{array}$ & $\begin{array}{l}(0.4181, \\
0.6228, \\
0.5819)\end{array}$ & $\begin{array}{l}(0.3345, \\
0.7155, \\
0.6655)\end{array}$ & $\begin{array}{l}0.4181, \\
0.6228, \\
0.5819) \\
\end{array}$ & $\begin{array}{l}(0.2509, \\
0.7991, \\
0.7491)\end{array}$ \\
\hline $\mathrm{C}_{4}$ & $\begin{array}{l}(0.0867, \\
0.9133, \\
0.9133)\end{array}$ & $\begin{array}{l}\text { (0.2481, } \\
0.8019 \\
0.7519)\end{array}$ & $\begin{array}{l}(0.1085, \\
0.8957, \\
0.8915)\end{array}$ & $\begin{array}{l}(0.0387, \\
0.9613, \\
0.9613)\end{array}$ & $\begin{array}{l}(0.0398, \\
0.9602, \\
0.9602)\end{array}$ & $\begin{array}{l}(0.4214, \\
0.6179, \\
0.5786)\end{array}$ & $\begin{array}{l}(0.0633, \\
0.9367, \\
0.9367)\end{array}$ & $\begin{array}{l}(0.8529 \\
0.1236 \\
0.1471)\end{array}$ & $\begin{array}{l}(0.0843, \\
0.9157, \\
0.9157)\end{array}$ \\
\hline $\mathrm{C}_{5}$ & $\begin{array}{l}(0.1785, \\
0.8607, \\
0.8215)\end{array}$ & $\begin{array}{l}(0.5356, \\
0.4466, \\
0.4644)\end{array}$ & $\begin{array}{l}(0.2678, \\
0.7822, \\
0.7322)\end{array}$ & $\begin{array}{l}(0.2232, \\
0.8268, \\
0.7768)\end{array}$ & $\begin{array}{l}(0.0446, \\
0.9554, \\
0.9554)\end{array}$ & $\begin{array}{l}(0.4463, \\
0.5805, \\
0.5537)\end{array}$ & $\begin{array}{l}(0.3571, \\
0.6929, \\
0.6429)\end{array}$ & $\begin{array}{l}(0.4463, \\
0.5805, \\
0.5537)\end{array}$ & $\begin{array}{l}(0.1785, \\
0.8607, \\
0.8215)\end{array}$ \\
\hline $\mathrm{C}_{6}$ & $\begin{array}{l}(0.1174, \\
0.8913, \\
0.8826)\end{array}$ & $\begin{array}{l}(0.7829, \\
0.1671, \\
0.2171)\end{array}$ & $\begin{array}{l}(0.3915, \\
0.6585, \\
0.6085)\end{array}$ & $\begin{array}{l}(0.0685, \\
0.9315, \\
0.9315)\end{array}$ & $\begin{array}{l}(0.0587, \\
0.9413, \\
0.9413)\end{array}$ & $\begin{array}{l}(0.2349, \\
0.8151, \\
0.7651)\end{array}$ & $\begin{array}{l}(0.2349, \\
0.8151, \\
0.7651)\end{array}$ & $\begin{array}{l}(0.2349, \\
0.8151, \\
0.7651)\end{array}$ & $\begin{array}{l}(0.2153, \\
0.8347, \\
0.7847)\end{array}$ \\
\hline $\mathrm{C}_{7}$ & $\begin{array}{l}(0.2912, \\
0.7588, \\
0.7088)\end{array}$ & $\begin{array}{l}(0.5096, \\
0.4856, \\
0.4904)\end{array}$ & $\begin{array}{l}(0.364, \\
0.686, \\
0.636)\end{array}$ & $\begin{array}{l}(0.2912, \\
0.7588, \\
0.7088)\end{array}$ & $\begin{array}{l}(0.0728, \\
0.9272, \\
0.9272)\end{array}$ & $\begin{array}{l}(0.2621, \\
0.7879, \\
0.7379)\end{array}$ & $\begin{array}{l}(0.5096, \\
0.4856, \\
0.4904)\end{array}$ & $\begin{array}{l}(0.2621, \\
0.7879, \\
0.7379)\end{array}$ & $\begin{array}{l}(0.1893, \\
0.8554, \\
0.8107)\end{array}$ \\
\hline $\mathrm{C}_{8}$ & $\begin{array}{l}(0.3519, \\
0.6981, \\
0.6481)\end{array}$ & $\begin{array}{l}(0.1408, \\
0.8796 \\
0.8592)\end{array}$ & $\begin{array}{l}(0.7038, \\
0.2462, \\
0.2962)\end{array}$ & $\begin{array}{l}(0.176, \\
0.862, \\
0.824)\end{array}$ & $\begin{array}{l}(0.176, \\
0.862, \\
0.824)\end{array}$ & $\begin{array}{l}(0.088, \\
0.912, \\
0.912)\end{array}$ & $\begin{array}{l}(0.5279, \\
0.4582, \\
0.4721)\end{array}$ & $\begin{array}{l}(0.088, \\
0.912, \\
0.912)\end{array}$ & $\begin{array}{l}(0.0704, \\
0.9296, \\
0.9296)\end{array}$ \\
\hline C9 & $\begin{array}{l}0.2631, \\
0.7869, \\
0.7369) \\
\end{array}$ & $\begin{array}{l}0.3508, \\
0.6992, \\
0.6492) \\
\end{array}$ & $\begin{array}{l}0.1754, \\
0.8623, \\
0.8246) \\
\end{array}$ & $\begin{array}{l}0.2631, \\
0.7869, \\
0.7369) \\
\end{array}$ & $\begin{array}{l}0.4385, \\
0.5922, \\
0.5615) \\
\end{array}$ & $\begin{array}{l}(0.3947, \\
0.6553, \\
0.6053)\end{array}$ & $\begin{array}{l}0.2193, \\
0.8307, \\
0.7807) \\
\end{array}$ & $\begin{array}{l}0.3947, \\
0.6553, \\
0.6053) \\
\end{array}$ & $\begin{array}{l}(0.3947, \\
0.6553, \\
0.6053)\end{array}$ \\
\hline$C_{10}$ & $\begin{array}{l}(0.1953, \\
0.8524, \\
0.8047)\end{array}$ & $\begin{array}{l}(0.3255, \\
0.7245, \\
0.6745)\end{array}$ & $\begin{array}{l}(0.2604, \\
0.7896, \\
0.7396)\end{array}$ & $\begin{array}{c}(0.1953, \\
0.8524, \\
0.8047)\end{array}$ & $\begin{array}{l}(0.1302, \\
0.8849, \\
0.8698)\end{array}$ & $\begin{array}{l}(0.5208, \\
0.4689, \\
0.4792)\end{array}$ & $\begin{array}{c}(0.1953, \\
0.8524, \\
0.8047)\end{array}$ & $\begin{array}{l}(0.5208, \\
0.4689, \\
0.4792)\end{array}$ & $\begin{array}{c}(0.3906, \\
0.6594, \\
0.6094)\end{array}$ \\
\hline$C_{11}$ & $\begin{array}{l}(0.0631, \\
0.9369, \\
0.9369)\end{array}$ & $\begin{array}{l}(0.2525, \\
0.7975, \\
0.7475)\end{array}$ & $\begin{array}{l}(0.1894, \\
0.8553, \\
0.8106)\end{array}$ & $\begin{array}{l}(0.0631, \\
0.9369, \\
0.9369)\end{array}$ & $\begin{array}{l}(0.3156, \\
0.7344, \\
0.6844)\end{array}$ & $\begin{array}{c}(0.4418, \\
0.5872, \\
0.5582)\end{array}$ & $\begin{array}{l}(0.0631, \\
0.9369, \\
0.9369)\end{array}$ & $\begin{array}{l}(0.6312, \\
0.3188, \\
0.3688)\end{array}$ & $\begin{array}{c}(0.4418, \\
0.5872, \\
0.5582)\end{array}$ \\
\hline$C_{12}$ & $\begin{array}{l}(0.0634, \\
0.9366, \\
0.9366)\end{array}$ & $\begin{array}{l}(0.1267, \\
0.8866, \\
0.8733)\end{array}$ & $\begin{array}{c}(0.1267, \\
0.8866, \\
0.8733)\end{array}$ & $\begin{array}{c}(0.0634, \\
0.9366, \\
0.9366)\end{array}$ & $\begin{array}{l}(0.3169, \\
0.7331, \\
0.6831)\end{array}$ & $\begin{array}{c}(0.507, \\
0.4895, \\
0.493)\end{array}$ & $\begin{array}{c}(0.0634, \\
0.9366, \\
0.9366)\end{array}$ & $\begin{array}{l}(0.6337, \\
0.3163, \\
0.3663)\end{array}$ & $\begin{array}{c}(0.4436, \\
0.5846, \\
0.5564)\end{array}$ \\
\hline $\mathrm{C}_{13}$ & $\begin{array}{l}(0.5401, \\
0.4399, \\
0.4599)\end{array}$ & $\begin{array}{l}(0.1543, \\
0.8728, \\
0.8457)\end{array}$ & $\begin{array}{l}(0.1543, \\
0.8728, \\
0.8457)\end{array}$ & $\begin{array}{c}(0.6172, \\
0.3328, \\
0.3828)\end{array}$ & $\begin{array}{l}(0.3858, \\
0.6642, \\
0.6142)\end{array}$ & $\begin{array}{l}(0.0772, \\
0.9228, \\
0.9228)\end{array}$ & $\begin{array}{l}(0.3086, \\
0.7414, \\
0.6914)\end{array}$ & $\begin{array}{l}(0.1543, \\
0.8728, \\
0.8457)\end{array}$ & $\begin{array}{c}(0.0772, \\
0.9228, \\
0.9228)\end{array}$ \\
\hline $\mathrm{C}_{14}$ & $\begin{array}{c}(0.4887, \\
0.517, \\
0.5113)\end{array}$ & $\begin{array}{l}(0.1833, \\
0.8584, \\
0.8167)\end{array}$ & $\begin{array}{c}(0.3665, \\
0.6835, \\
0.6335)\end{array}$ & $\begin{array}{l}(0.4276, \\
0.6086, \\
0.5724)\end{array}$ & $\begin{array}{l}(0.0611, \\
0.9389, \\
0.9389)\end{array}$ & $\begin{array}{c}(0.1222, \\
0.8889, \\
0.8778)\end{array}$ & $\begin{array}{l}(0.6108, \\
0.3392, \\
0.3892)\end{array}$ & $\begin{array}{l}(0.1222, \\
0.8889, \\
0.8778)\end{array}$ & $\begin{array}{c}(0.0611, \\
0.9389, \\
0.9389)\end{array}$ \\
\hline $\mathrm{C}_{15}$ & $\begin{array}{l}(0.0618, \\
0.9382, \\
0.9382)\end{array}$ & $\begin{array}{l}(0.6178, \\
0.3322, \\
0.3822)\end{array}$ & $\begin{array}{c}(0.4942, \\
0.5086, \\
0.5058)\end{array}$ & $\begin{array}{l}(0.0618, \\
0.9382, \\
0.9382)\end{array}$ & $\begin{array}{l}(0.1853, \\
0.8573, \\
0.8147)\end{array}$ & $\begin{array}{l}(0.3089, \\
0.7411, \\
0.6911)\end{array}$ & $\begin{array}{l}(0.0618, \\
0.9382, \\
0.9382)\end{array}$ & $\begin{array}{l}(0.3707, \\
0.6793, \\
0.6293)\end{array}$ & $\begin{array}{c}(0.3089, \\
0.7411, \\
0.6911)\end{array}$ \\
\hline
\end{tabular}

reference point and the neutrosophic full multiplicative form are presented in Table 5. The final ranks for MULTIMOORA-mGqNN approach were determined by applying the dominance theory.

Additionally, a verification analysis was done to test the reliability of the proposed approach. For this purposed ranking results for the same alternatives (cable roots) were calculated with the CoCoSo method (Yazdani et al., 2019) and compared with the final ranks of the MULTIMOORA-mGqNN approach. Results presented in Table 6 allows us to conclude that MULTIMOORA-mGqNN provides a robust and reliable framework for different MCDM tasks.

In the solution for the Cable Roots Management in Chemical Industry, the alternative Concrete threshold (CTH) is shown as the optimal installation variant for the examined cable route. This alternative differs from the others by a low construction cost and sufficient technical reliability. 
Table 5. Results of the MULTIMOORA- mGqNN approach

\begin{tabular}{|c|c|c|c|c|c|c|c|}
\hline & \multicolumn{2}{|c|}{ mGqNN ratio system } & \multicolumn{2}{c|}{ mGqNN reference point } & \multicolumn{2}{c|}{ mGqNN full multiplicative } & \\
\hline Alternative & Value & Rank & Value & Rank & Value & Rank & Final Rank \\
\hline CT & 0.5897 & 3 & 0.9829 & $4-5$ & 0.18891 & 5 & $\mathbf{5}$ \\
\hline WCC & 0.5262 & 9 & 0.9941 & 9 & 0.01123 & 7 & $\mathbf{9}$ \\
\hline NAC & 0.5635 & 6 & 0.9856 & 6 & 1.45584 & 4 & $\mathbf{6}$ \\
\hline GL & 0.5918 & 2 & 0.9791 & 3 & 10.09717 & 3 & $\mathbf{2}$ \\
\hline CTH & 0.5973 & 1 & 0.9865 & 7 & 16.89987 & 2 & $\mathbf{1}$ \\
\hline CB & 0.5538 & 7 & 0.9689 & $1-2$ & 0.00004 & 8 & $\mathbf{3}$ \\
\hline CMS & 0.5732 & 4 & 0.9829 & $4-5$ & 1271.15030 & 1 & $\mathbf{4}$ \\
\hline CPB & 0.5342 & 8 & 0.9689 & $1-2$ & 0.00000 & 9 & $\mathbf{8}$ \\
\hline CF & 0.566 & 5 & 0.9931 & 8 & 0.02306 & 6 & $\mathbf{7}$ \\
\hline
\end{tabular}

Table 6. Verification analysis presenting the final ranks of the analysed alternatives

\begin{tabular}{|c|c|c|c|c|c|c|c|c|c|}
\hline & CT & WCC & NAC & GL & CTH & CB & CMS & CPB & CF \\
\hline MULTIMOORA-mGqNN & 5 & 9 & 6 & 2 & 1 & 3 & 4 & 8 & 7 \\
\hline CoCoSo & 3 & 8 & 5 & 2 & 1 & 7 & 4 & 9 & 6 \\
\hline
\end{tabular}

\section{Results and Conclusions}

The increased interest in the mathematical modelling techniques that can be applied to find solutions for the various multicriteria decisionmaking problems that deal with the uncertainty and vagueness of the initial information can be seen. Single valued neutrosophic sets are considered as the effective tool to express uncertainty information; however, in some cases it lacks the desirable generality and flexibility. The m-generalized q-neutrosophic sets were recently proposed to deal with this situation. The m-generalized q-neutrosophic sets work as the generalisation of fuzzy set, Pythagorean fuzzy set, intuitionistic fuzzy set, q-rung orthopair fuzzy set, single-valued neutrosophic set, single-valued n-hyperspherical neutrosophic set and singlevalued spherical neutrosophic set.

In this paper, the MULTIMOORA modification under the m-generalized q-neutrosophic numbers ( $\mathrm{mGqNN}$ ) is proposed. This novel approach was applied to rank nine cable-laying methods, that differs in terms of the territorial and site plan parameters, construction-related parameters, environmental influences and operational parameters. Concrete threshold open cable laying alternative was identified as the best of the analysed solutions for the application in the chemical industry. The numerical example also showed that MULTIMOORA-mGqNN provides a robust framework that can be applied to solve different MCDM problems.

\section{REFERENCES}

Atanassov, K. T. (1986). Intuitionistic fuzzy sets, Fuzzy Sets and Systems, 20, 87-96.

Aydemir, S. B. \& Yilmaz Gündüz, S. (2020). Extension of multi-Moora method with some q-rung orthopair fuzzy Dombi prioritized weighted aggregation operators for multi-attribute decision making, Soft Computing, 24, 18545-18563. DOI: 10.1007/ s00500-020-05091-4

Baležentis, T., Zeng, S. \& Balezentis, A. (2014). MULTIMOORA-IFN: a MCDM method based on intuitionistic fuzzy number for performance management, Economic Computation and Economic Cybernetics Studies and Research, 48(4), 85-102.

Brauers, W. K. M., Baležentis, A. \& Baležentis, T. (2011). Multimoora for the EU member states updated with fuzzy number theory, Technological and Economic Development of Economy, 17(2), 259-290. DOI: $10.3846 / 20294913.2011 .580566$

Brauers, W. K. M. \& Zavadskas, E. K. (2011). Multimoora Optimization Used to Decide on a Bank 
Loan to Buy Property, Technological and Economic Development of Economy, 17, 174-188. DOI: $10.3846 / 13928619.2011 .560632$

Liang, A., Darko, A. P. \& Zeng, J. (2020). Intervalvalued pythagorean fuzzy power average-based MULTIMOORA method for multicriteria decisionmaking, Journal of Experimental \& Theoretical Artificial Intelligence, 32(5), 845-874. DOI: 10.1080/0952813X.2019.1694589

Liao, Z., Liao, H., Gou, X., Xu, Z. \& Zavadskas, E. K. (2019). A hesitant fuzzy linguistic Choquet integralbased MULTIMOORA method for multiple criteria decision making and its application in talent selection, Economic Computation and Economic Cybernetics Studies and Research, 53(2), 113-130.

Maghsoodi, I. A., Azizi-ari, I., Barzegar-Kasani, Z., Azad, M., Zavadskas, E. K. \& Antucheviciene, J. (2019). Evaluation of the Influencing Factors on Job Satisfaction Based on Combination of PLS-SEM and F-MULTIMOORA Approach, Symmetry, 11(1), 24. DOI: $10.3390 /$ sym 11010024

Saha, A., Smarandache, F., Baidya, J. \& Dutta, D. (2020). MADM Using m-Generalized q-Neutrosophic Sets, Neutrosophic Sets and Systems, 35(1), 252-268.

Smarandache, F. A. (1999). Unifying Field in Logics. Neutrosophy: Neutrosophic Probability, Set and Logic. American Research Press: Rehoboth, DE, USA.

Smarandache, F. (2019). Neutrosophic set is a generalization of intuitionistic fuzzy set, inconsistent intuitionistic fuzzy set, pythagorean fuzzy set, q-rung orthopair fuzzy set, spherical fuzzy set and n-hyperbolic fuzzy set while neutrosophication is a generalization of regret theory, grey system theory and three ways decision, Journal of New Theory, 29, 1-35.

Stanujkic, D., Karabasevic, D., Zavadskas, E. K., Smarandache, F. \& Brauers, W. K. (2019). A Bipolar Fuzzy Extension of the MULTIMOORA Method, Informatica, 30(1), 135-152. DOI:10.15388/ Informatica.2019.201

Stanujkic, D., Zavadskas, E. K., Smarandache, F., Brauers, W. K. \& Karabasevic, D. (2017). A Neutrosophic Extension of the MULTIMOORA Method, Informatica, 28(1), 181-192. DOI: 10.15388/ Informatica.2017.125
Wang, H., Smarandache, F., Zhang, Y. Q. \& Sunderraman, R. (2010). Single valued neutrosophic sets, Multi-space and Multi-structure, 4, 410-413.

Yager, R. R. (2013). Pythagorean fuzzy subsets. In Joint IFSA World Congress and NAFIPS Annual Meeting (IFSA/NAFIPS), Edmonton, AB, 2013 (pp. 57-61). DOI: 10.1109/IFSA-NAFIPS.2013.6608375

Yager, R. R. (2017). Generalized Orthopair Fuzzy Sets, IEEE Transactions on Fuzzy Systems, 25(5), 1222-1230. DOI: 10.1109/TFUZZ.2016.2604005

Yazdani, M., Zarate, P., Zavadskas, E. K. \& Turskis, Z. (2019). A combined compromise solution (CoCoSo) method for multi-criteria decision-making problems, Management Decision, 57(9), 2501-2519. DOI: 10.1108/MD-05-2017-0458

Zadeh, L. A. (1965). Fuzzy Sets, Information and Control, 8, 338-353. DOI: 10.1016/S00199958(65)90241-X

Zavadskas, E. K., Antucheviciene, J., Hajiagha, S. H. R. \& Hashemi, S. S. (2015). The Interval-Valued Intuitionistic Fuzzy MULTIMOORA Method for Group Decision Making in Engineering, Mathematical Problems in Engineering, Article ID 560690. DOI: $10.1155 / 2015 / 560690$

Zavadskas, E. K., Bausys, R., Juodagalvienè, B. \& Garnytė-Sapranavičienè, I. (2017). Model for residential house element and material selection by neutrosophic MULTIMOORA method, Engineering Applications of Artificial Intelligence, 64, 315-324.

Zavadskas, E. K., Čereška, A., Matijošius, J., Rimkus, A. \& Bausys, R. (2019). Internal Combustion Engine Analysis of Energy Ecological Parameters by Neutrosophic MULTIMOORA and SWARA Methods, Energies, 12, 1415.

Zhu, Y. (2020). Multiple-attribute Decisionmaking of Q-Rung Orthopair Fuzzy Sets Based on Hamacher Norm and Improved MULTIMOORA. In Proceedings of the 4th International Conference on Computer Science and Application Engineering (CSAE 2020). Association for Computing Machinery, New York, NY, USA, Article 160 (pp. 1-6). DOI: $10.1145 / 3424978.3425145$

https://www.sic.ici.ro 